\title{
Test Plan for the Technology Maturation of Supersonic Inflatable Aerodynamic Decelerators
}

\author{
Jenny R. Kelly* \\ Georgia Institute of Technology, Atlanta, GA 30332-0150 \\ and \\ Juan R. Cruz \\ NASA Langley Research Center, Hampton, VA 23681-2199
}

\begin{abstract}
Supersonic inflatable aerodynamic decelerators (IADs) are drag devices intended to be deployed at high Mach numbers. In the application considered here they assist in the descent and landing of spacecraft on Mars. Although promising, present IAD technology is not yet sufficiently mature for use in the near future. This paper describes a technology maturation plan for tension cone IADs using subscale test articles to reduce development costs. As envisioned, the proposed test plan includes three phases: wind tunnel tests (subsonic), unpowered high-altitude flight tests (transonic), and powered high-altitude tests (supersonic). This test plan is based on a building block approach in which successful completion of each phase adds to the understanding of the behavior of IADs and reduces the risk of the subsequent, more expensive phases. By properly scaling the IADs, test articles of the same size and nearly the same construction can be used for all three phases. The final phase is a dynamically scaled flight test with IAD deployment at the same Mach number as the full-scale vehicle on Mars. Two full-scale example cases are presented: one for a single-stage system (15 $\mathrm{m}$ dia. IAD to subsonic retropropulsion), and another for a two-stage system (10.5 m dia. IAD to subsonic parachute). Using scale factors of 0.333 and 0.476 yield subscale test IADs of $5 \mathrm{~m}$ dia. The dynamically scaled powered flight test starts at Mach 4 and an altitude of $33.5 \mathrm{~km}$. Existing balloons and rocket motors are shown to be adequate to meet the required test conditions.
\end{abstract}

\section{Nomenclature}

$\begin{array}{ll}a & =\text { speed of sound } \\ a_{S D} & =\text { speed of sound at start of IAD deployment } \\ d & =\text { aeroshell diameter } \\ d_{I A D} & =\text { IAD diameter } \\ h & =\text { altitude } \\ h_{0} & =\text { test initiation altitude } \\ h_{S D} & =\text { altitude at start of IAD deployment } \\ m_{v e h i c l e} & =\text { test vehicle mass } \\ M & =\text { Mach number } \\ M_{S D} & =\text { Mach number at start of IAD deployment } \\ N & =\text { test-to-flight ratio } \\ q_{S D} & =\text { dynamic pressure at start of IAD deployment } \\ t & =\text { time } \\ t_{0} & =\text { time at test initiation } \\ t_{c} & =\text { coast time } \\ t_{S D} & =\text { time at start of IAD deployment } \\ \beta & =\text { ballistic coefficient } \\ \theta_{0} & =\text { test initiation elevation angle } \\ \rho & =\text { atmospheric density } \\ \rho_{S D} & =\text { atmospheric density at start of IAD deployment }\end{array}$

\footnotetext{
*Graduate Student, Guggenheim School of Aerospace Engineering, AIAA Student Member, Jenny.Kelly@GATech.edu

${ }^{\dagger}$ Aerospace Engineer, Atmospheric Flight and Entry Systems Branch, Juan.R.Cruz@NASA.gov
} 


ATK $=$ Alliant Techsystems Inc.
BLDT $=$ Balloon Launched Decelerator Test
CFD $=$ Computational Fluid Dynamics
FEM $=$ Finite Element Method
FSI $=$ Fluid-Structures Interaction
IAD $=$ Inflatable Aerodynamic Decelerator
NFAC $=$ National Full-Scale Aerodynamics Complex

\section{Introduction}

Supersonic inflatable aerodynamic decelerators (IADs) are drag devices intended to be deployed at high Mach numbers $(2 \leq M \leq 5)$. In the application considered here they assist in the descent and landing of large robotic spacecraft on Mars. Although promising, present IAD technology is not sufficiently mature for use in the near future (i.e., for missions to be flown in the next 5 to 10 years). This paper describes a technology maturation plan for tension cone IADs using subscale test articles.

A tension cone IAD consists of an inflatable torus attached to the aeroshell by a tension shell as shown in Figure $1 .^{*}$ The IAD is stowed around the perimeter of the aeroshell. Once the aeroshell has entered the atmosphere and decelerated to high supersonic speed (i.e., $M \leq 5$ ), the IAD is deployed and inflated using an on-board gas source. The additional drag generated by the inflated IAD rapidly decelerates the aeroshell to subsonic speeds.

As envisioned, the proposed technology maturation plan includes three phases: wind tunnel tests (subsonic), unpowered high-altitude flight tests (transonic), and powered high-altitude tests (supersonic). Each phase is a building block, addressing specific technology challenges and providing data for planning and reducing the risk of the next (more expensive) phase. All three phases use subscale IAD test articles of the same size and identical construction to the greatest extent possible. By using subscale IADs testing costs are reduced. The test article scale is selected to be as small as possible while still being structurally representative of full-scale IADs (i.e., similar construction materials and fabrication techniques) and being Mach scaled for the powered high-altitude flight tests.

\section{Test Plan Objectives}

The proposed test plan intends to mature IAD technology in the following six areas:

Packing: The IAD must be packaged in the least amount of volume possible and be in a region where it can be protected from aeroheating during entry. In addition, the packaging must allow for the proper deployment and inflation of the IAD.

Deployment and Inflation: ${ }^{\S}$ Deployment and inflation must proceed in an organized, symmetric, and timely manner. Undesired contact with the aeroshell must not occur. The time history of drag during deployment and inflation must be known. An appropriate inflation gas source must be available that provides the necessary pressures and flow rates.

Structural Integrity: The IAD must be capable of sustaining the loads imposed on it during deployment and inflation as well as during descent without damage that compromises its function.

Required Inflation Pressure: The minimum torus pressure needed to maintain the IAD in its fully-inflated configuration must be known in order to size the inflation gas source and for stress analyses of the torus.

Aerodynamic Performance: The drag coefficient of the IAD as a function of Mach number must be known for accurate trajectory analyses.

\footnotetext{
*All subsequent references to IADs in this paper imply the tension cone type. It is also assumed that the aeroshell is of the blunt-body type shown in Figure 1.

${ }^{\S}$ Unlike parachutes, deployment and inflation are not easily separated as discrete events for an IAD. Thus, in this paper deployment and inflation are considered to be a single event.
} 
Flight Dynamics: The flight dynamics of the aeroshel1/IAD combination must be understood for landing system design analyses.

Design, Analysis, and Fabrication: The design of the subscale IAD test articles will help mature the computational fluid dynamic (CFD), finite element method (FEM), and fluid-structures interaction (FSI) analyses needed to develop full-scale IADs. Test data obtained during execution of this test plan will provide a validation database for these analyses. Challenges involving materials and manufacturing technology will need to be addressed to build the subscale IAD test articles. Experience and data obtained in building the subscale test articles will improve the fidelity of mass estimation models.

\section{Test IAD Sizing}

The proposed flight tests are designed to simulate IAD operation on Mars. A Mars reference vehicle and its trajectory were defined, and scaling laws were applied to size two test vehicle options.

\section{A. Mars Reference Vehicle and Trajectory}

The selected Mars reference trajectory used initial conditions obtained from the trajectory shown in Figure 17 of Reference 1 for a ballistic coefficient $(\beta)$ of $200 \mathrm{~kg} / \mathrm{m}^{3}$. These initial conditions were Mach 4 at an altitude of 10 $\mathrm{km}$. The atmospheric model used to compute the trajectory in Reference 1 was not available, but an adequate approximation was obtained using the atmospheric model proposed by Seiff ${ }^{2}$ for the southern summer on Mars. The selected Mars reference vehicle was a $70^{\circ}$ sphere cone aeroshell (based on the geometry of the Mars Science Laboratory) with a diameter of $4.5 \mathrm{~m}$ and an assumed drag coefficient of 1.6 at Mach numbers above 2. Given these parameters and the ballistic coefficient, the reference vehicle mass was calculated to be $5,089 \mathrm{~kg}$.

Both single-stage and two-stage IAD systems were considered for analysis. The single-stage system employs a large-diameter IAD to decelerate from Mach 4 to an acceptable propulsive descent regime $(125 \mathrm{~m} / \mathrm{s}$ at an altitude of $1 \mathrm{~km}$ ). The two-stage system uses a smaller diameter IAD to decelerate the vehicle into an acceptable state (Mach 0.8 at an altitude of $6.4 \mathrm{~km}$ ) for deployment of a subsonic parachute as the second stage. The IAD diameters selected for each of these systems allow the vehicles to meet the desired end conditions. For the single-stage and two-stage vehicles, the IAD diameters are $15.0 \mathrm{~m}$ and $10.5 \mathrm{~m}$, respectively. The corresponding Mars trajectories, with initial and end conditions noted, are shown in Figure 2.

\section{B. Scaling Laws}

It is often desirable to test a vehicle in subscale to minimize cost. By maintaining the same value of key parameters between the subscale and full-scale vehicles, the full-scale flight vehicle's behavior can be predicted from the results obtained from the subscale test vehicle. In the present investigation, these parameters are combined into three scaling laws that were used to design a subscale vehicle and choose appropriate test parameters. In developing these scaling laws, it was assumed that the test vehicle was geometrically similar to the flight vehicle. The scaling is exact at IAD deployment, and closely matched throughout the supersonic portion of the trajectory.

To match the flight dynamics of the full-scale vehicle, the scaling law developed in Reference 3 and presented in Equation (1) was used.

$$
\frac{N_{m}}{N_{\rho} N_{d}^{3}}=1
$$

The quantities represented by $N$ are ratios of Earth test to Mars flight parameters. For example, the mass parameter, $N_{m}$, is the ratio of the test vehicle mass to the flight vehicle mass. Likewise, $N_{\rho}$ and $N_{d}$ are test-to-flight ratios of atmospheric density and aeroshell diameter, respectively. To achieve aerodynamic similarity, the full-scale flight and subscale test Mach number need to be identical (i.e., Mach scaling). The scaling law reflecting this Mach number identity can be written as shown in Equation (2).

$$
N_{M}=1
$$

Invoking kinematic similarity and the Mach scaling requirement of Equation (2) implies that

$$
\frac{N_{t} N_{a}}{N_{d}}=1
$$

where $N_{t}$ and $N_{a}$ are test-to-flight ratios of time and speed of sound, respectively. Note that Equation (3a) can be rewritten as shown in Equation (3b), indicating that the time response of the test vehicle is faster than that of the 
flight vehicle. This occurs because for a subscale test vehicle $N_{d}<1$ and $N_{a}>1$ when testing on Earth for a flight to be conducted on Mars.

$$
N_{t}=\frac{t_{\text {test }}}{t_{\text {flight }}}=\frac{N_{d}}{N_{a}}
$$

\section{Test Vehicle and IAD}

The IAD diameters for the Mars flight vehicles were determined to be $15.0 \mathrm{~m}$ for the single-stage vehicle and $10.5 \mathrm{~m}$ for the two-stage vehicle. It was decided that the test vehicles would both utilize a $5.0 \mathrm{~m}$ diameter IAD. Thus, the single-stage test vehicle is a $1 / 3$-scale vehicle $\left(N_{d}=5.0 / 15.0=0.333\right)$ and the two-stage vehicle is a nearly $1 / 2$-scale vehicle $\left(N_{d}=10.5 / 15.0=0.476\right)$. A test-to-flight density ratio $\left(N_{\rho}\right)$ of 0.675 was selected and used for both vehicles since it yielded reasonable test vehicle masses. The atmospheric density for test was then calculated from $N_{\rho}$ and the desired Mars density at IAD deployment $\left(7.42 \times 10^{-3} \mathrm{~kg} / \mathrm{m}^{3}\right.$ at $10 \mathrm{~km}$ altitude on Mars $\left.{ }^{2}\right)$. This yielded an Earth test atmospheric density of $5.01 \times 10^{-3} \mathrm{~kg} / \mathrm{m}^{3}$, which corresponds to an altitude of $33,503 \mathrm{~m}$ in the 1976 Standard Atmosphere $;{ }^{4}$ this altitude was defined as the test condition altitude. The test vehicle masses were then calculated from the Mars flight vehicle mass and the test-to-flight ratios of diameter and density according to the scaling law in Equation (1). Both the flight and test vehicles are described in Table 1. The initial conditions for the Mars flight and test are given in Table 2. Other vehicle parameters, such as the mass moments of inertia, will need to be scaled appropriately (see Reference 5 for a complete list of scaling laws for a Mach scaled test).

The same size IAD (5.0 m diameter) will be used for all three tests. However, the mass and flight-test initial conditions in Tables 1 and 2 will only be used for the powered high-altitude flight tests described in section VI. The wind tunnel tests described in section IV will be conducted at subsonic speeds with a rigid support. The unpowered high-altitude flight tests described in section V will be initiated at transonic Mach numbers with a vehicle of much greater mass than specified in Table 1.

\section{Wind Tunnel Tests}

\section{A. Test Objectives}

The principal goals of the wind tunnel tests are to address the packing, deployment and inflation, and structural integrity test plan objectives described in section II. These objectives can be achieved by testing the subscale models in the 40- by $80-\mathrm{ft}$ (12.2- by 24.4-m) wind tunnel test section of the National Full-Scale Aerodynamics Complex (NFAC).

\section{B. Test Description}

The NFAC has been used in several programs to develop and qualify aerodynamic decelerators. ${ }^{6-8}$ Some of the advantages of testing aerodynamic decelerators in a wind tunnel include the ability to obtain high-quality video coverage of dynamic events such as deployment and inflation, being able to reset and repeat a test relatively quickly, and having precise control over the test conditions (e.g., angle of attack, dynamic pressure).

Figure 3 shows the proposed test setup in the 40 - by 80 -foot test section of the NFAC. ${ }^{9}$ The aeroshell is mounted facing the airstream on top of a specially built tripod structure. Prior to deployment the IAD is packaged around the perimeter of the aeroshell. A load cell within the aeroshell measures the axial forces on the aeroshell during deployment, inflation, and in steady state. Facility-provided air is used to inflate the torus. With this test setup, repeated deployment and inflation tests can be conducted with extensive video coverage (which is difficult to obtain during flight tests). These videos will be useful in the development of appropriate packing techniques to obtain reliable deployment and inflation.

Another purpose of the wind tunnel test is to obtain initial structural integrity data on the test IAD. By adjusting the dynamic pressure of the wind tunnel test to account for the difference in drag coefficient due to Mach number, the same peak aerodynamic force that the IAD will experience during the high-altitude flight tests can be applied. These forces are 78.2 and $87.4 \mathrm{kN}$ for the single- and two-stage IADs, respectively. To match these forces, wind tunnel dynamic pressures of approximately 4.9 and $5.5 \mathrm{kPa}$ will be needed for the single-stage and two-stage IADs, respectively. These dynamic pressures are well within the maximum wind tunnel capability of $12.5 \mathrm{kPa}$. This margin in dynamic pressure capability can be used to generate a higher total maximum axial aerodynamic force to account for factors of safety on the IAD structure. The required peak aerodynamic force can be applied suddenly by performing a deployment and inflation, or in a quasi-steady manner by starting with an inflated torus and slowly

I“"NFAC,” Retrieved February 20, 2008, from NASA Ames Research Center website: www.windtunnels.arc.nasa.gov/nfac.html. 
increasing the dynamic pressure in the tunnel. NASA has made use of NFAC for the structural qualification of supersonic parachutes for the Mars Exploration Rover $^{7}$ and Mars Science Laboratory ${ }^{8}$ missions. ${ }^{* *}$

Although the wind tunnel test provides useful data in a low-risk and relatively low-cost environment (as compared to the flight tests), there are two important limitations of this test that need to be considered. First, the wind tunnel test is conducted at subsonic speed; thus the aerodynamic pressure distribution on the IAD is not identical to that which it will experience during supersonic flight. This difference in aerodynamic pressure distribution will modify the stress distribution on the IAD structure and will have an effect on the minimum inflation pressure required to keep the torus from collapsing. Second, because the NFAC is an atmospheric tunnel operating at sea level, the external pressure is significantly higher than will be experienced during the high-altitude flight tests. Thus, to maintain the necessary pressure differential, the torus will have to be inflated to a higher absolute pressure. This is unlikely to be a structural problem. However, the additional fluid mass (due to the higher pressure) required to inflate the torus may limit how rapidly the torus can be inflated, and/or may require more inflation tubes than those needed for the IADs used for the high-altitude flight tests.

\section{Unpowered High-Altitude Flight Tests}

\section{A. Test Objectives}

The unpowered high-altitude flight tests have four principal test objectives. First, they will demonstrate that the deployment and inflation of the IAD, as developed during the wind tunnel tests, works as intended in a low-density atmosphere. Second, they will demonstrate the proper operation of the inflation gas source required for flight tests. Third, the tests will verify the structural integrity of the IAD during an in-flight deployment and inflation at the design peak aerodynamic force in a low-density atmosphere. Fourth, because the unpowered and powered high-altitude flight tests share many common elements, the unpowered high-altitude flight tests reduce risks for the subsequent, and significantly more expensive, powered high-altitude flight tests.

\section{B. Concept of Operation}

The flight test concept of operation is shown in Figure 4. A balloon lifts the test vehicle to the test initiation altitude, $h_{0}$, and releases it. During free fall, a drogue parachute is used to limit the oscillations of the test vehicle; this drogue parachute is released just prior to IAD deployment. The vehicle drops in free fall until a predetermined test condition is reached, at which point the IAD deploys and inflates.

\section{Analysis and Results}

For these tests the mass of the vehicles is increased beyond that given in Table 1. The goal is to obtain a sufficiently high dynamic pressure to match the peak aerodynamic forces that will be experienced by the vehicles during deployment in the powered high-altitude flight tests. These peak aerodynamic forces are 78.2 for the single-stage vehicle and $87.4 \mathrm{kN}$ for the two-stage vehicle.

Analyses were performed to determine the test vehicle mass, $m_{\text {vehicle }}$, and the time at the start of IAD deployment, $t_{S D}$, required to match the peak aerodynamic forces during deployment and inflation. The balloons chosen for use with each test vehicle were selected to correspond to the balloons required for the powered high-altitude drop tests discussed in section VI. These were the NASA standard 0.33 and 1.11 million-cubic-meter balloons for the singleand two-stage vehicles, respectively. The test vehicle mass was constrained such that the suspended mass (which includes the vehicle and miscellaneous balloon system related overhead mass) would not exceed the balloon's capability. Deployment and inflation of the IAD was assumed to occur over 0.75 and 1.07 seconds for the one- and two-stage vehicles, respectively. These times are the same as those expected during the powered high-altitude flight test. From the multiple combinations of $m_{\text {vehicle }}$ and $t_{S D}$ that could achieve the desired peak aerodynamic force during deployment and inflation, the values shown in Table 3 were chosen. The initial drop altitude, altitude at the start of IAD deployment, and Mach number at the start of IAD deployment are also given in Table 3.

Note that the values of $m_{\text {vehicle }}$ in Table 3 are much greater than those in Table 1 . These larger masses were needed to meet the requirement of matching peak aerodynamic forces during deployment and inflation with those in the corresponding powered high-altitude flight tests. A volumetric check shows that the additional mass can be accommodated in the heatshield of the vehicles by using a suitably heavy material such as steel. However, these heavier masses yield vehicles that do not match the scaling law in Equation (1). Thus, the vehicles in the unpowered high-altitude flight tests are not dynamically scaled.

\footnotetext{
${ }^{* *}$ Both of these missions used the larger 80 - by $120-\mathrm{ft}(24.4-$ by $36.6-\mathrm{m})$ test section of NFAC. For the tests proposed here the maximum dynamic pressure of this larger test section $(1.6 \mathrm{kPa})$ is not high enough.
} 


\section{Powered High-Altitude Flight Tests}

\section{A. Test Objectives}

The final phase of the proposed test plan is a series of powered high-altitude flight tests at the correct Mach number with dynamically scaled vehicles as defined in section III.C. With this phase all of the test plan objectives listed in section II are addressed. Particularly important results obtained from this test phase include supersonic deployment and inflation characteristics, aerodynamic performance, and flight dynamics data that can be scaled and applied to the full-scale flight vehicle on Mars.

\section{B. Concept of Operation}

The flight test concept of operation is shown in Figure 5. It is based on the Viking Balloon Launched Decelerator Test (BLDT) ${ }^{10}$ technique. The test vehicle is suspended from the balloon at the appropriate initial elevation angle, $\theta_{0}$ (i.e., the angle between the aeroshell axis of symmetry and the horizon). The balloon lifts the vehicle to the test initiation altitude, $h_{0}$, and releases it without inducing a tip-off rotation. The initial elevation angle is assumed to remain constant during the two-second free-fall drop since the vehicle falls for a relatively short time period in a very low-density atmosphere in which significant aerodynamic forces and moments will not be generated. During the two-second free-fall drop small rocket motors induce a roll rate to spin-stabilize the vehicle. After the two-second drop, a solid rocket motor ignites and accelerates the vehicle to supersonic speed, exceeding the test condition Mach number. When the rocket motor burns out, the vehicle's spin-stabilization roll rate is brought to near zero using another set of small rocket motors. The vehicle coasts until the test condition Mach number and altitude are met, at which point the IAD deploys and inflates. Eventually the vehicle descends to the ground and is recovered.

\section{Analysis}

Trajectory analyses were performed to determine the values of test initiation altitude and elevation angle. For each analysis, a set of test hardware (i.e., test vehicle, solid rocket motor, and NASA standard balloon) was specified.

\section{Solid Rocket Motors}

The solid rocket motors used in this study were selected from the ATK STAR ${ }^{\mathrm{TM}}$ series ${ }^{11}$ based on the total impulse required to accelerate the test vehicle to Mach 4. Table 4 lists characteristics of the rocket motor selected for each vehicle.

\section{NASA Standard Balloons}

Six balloons were selected for study from the set of currently available NASA standard balloons." A balloon's maximum achievable altitude was based on the suspended mass, which includes the vehicle (as given in Table 1), rocket motor propellant, and miscellaneous balloon system related overhead mass.

\section{Optimization}

Two-degree-of-freedom trajectory analyses were conducted for each test vehicle and balloon combination. The purpose of the analysis was to determine the optimal values for the initial altitude, $h_{0}$, and elevation angle, $\theta_{0}$, at which the test vehicle was released from the balloon.

The trajectory analysis was performed subject to certain constraints. At the time of IAD deployment, the test condition Mach number and altitude had to be met. In addition, the initial elevation angle was limited to the range $0 \leq \theta_{0} \leq 90^{\circ}$. Inflation of the IAD was assumed to last for three seconds for the full-scale flight vehicle; the corresponding inflation times for the test vehicles were calculated based on Equation (3b).

It was determined that multiple combinations of $h_{0}$ and $\theta_{0}$ could achieve the desired test condition. To distinguish between these cases, the optimal combination of $h_{0}$ and $\theta_{0}$ was defined as the case for which coast time (the time from solid rocket motor burnout to start of IAD deployment) was maximized. A longer coast time is desirable because it provides more time for completion of the de-spin rocket burn and serves as design margin. Exploration of the design space revealed that longer coast times occurred at higher initial altitudes. Thus the optimal

"Pierce, D. L., "Balloon suspended load capability," Retrieved August 1, 2008, from Wallops Flight Facility website: http://sites.wff.nasa.gov/code820/suspendedcapability.html. 
solution for a single vehicle and balloon combination could be found at the maximum altitude attainable by that balloon, which is a function of the suspended mass.

\section{Results}

The results obtained from the trajectory analysis provided insight into selection of the appropriate balloon. In general, increasing the balloon's capacity (and thus the maximum achievable initial altitude) resulted in a longer coast time. A minimum coast time of three seconds was assumed, and the smallest volume (and therefore least expensive) balloon that could provide this minimum coast time was chosen for each vehicle. These were the 0.33 and 1.11 million-cubic-meter balloons for the single- and two-stage vehicles, respectively. The initial values of $h_{0}$ and $\theta_{0}$, and the resulting coast times, are listed in Table 5 for each set of test hardware. Note that these vehicle, rocket and balloon combinations are just two of many feasible solutions.

The trajectory analyses yield altitude versus velocity profiles. Plots of these profiles are shown for each vehicle in Figures 6 and 7, with times of critical test flight events indicated. The peak aerodynamic forces during deployment and inflation were $78.2 \mathrm{kN}$ for the single-stage vehicle and $87.4 \mathrm{kN}$ for the two-stage vehicle. These aerodynamic forces impose 62.7 and 24.0 sensed g's on the single- and two-stage vehicles. Figure 8 shows the results of a preliminary sizing check that was performed to confirm that the rocket motors could be accommodated in the scaled aeroshells. Although additional analyses and design need to be conducted, the results presented here show that conducting a Mach and dynamically scaled flight test is plausible with existing balloons and rocket motors.

\section{Concluding Remarks}

A three-phase test plan has been outlined that allows for the maturation of tension cone IADs through the use of subscale test articles. This test plan is based on a building block approach in which successful completion of each phase adds to the understanding of the behavior of IADs and reduces the risk of the subsequent, more expensive phases. By properly scaling the IADs, test articles of the same size and nearly the same construction can be used for all three phases. The final phase is a dynamically scaled flight test with IAD deployment at the same Mach number as the full-scale vehicle on Mars. Successful completion of this final phase should provide a valuable stepping-stone for the development of an actual flight vehicle for Mars. Variations of this test plan should be applicable to the maturation of other types of IADs such as stacked toroids, attached isotensoids, and trailing isotensoids.

Although the basic feasibility of the test plan has been established by the calculations presented, many details remain to be worked out. The structural scaling of the IAD will be an important aspect of the subscale IAD design. Aerothermal considerations at high Mach numbers must be addressed. Suitable gas sources need to be developed to support the unpowered and powered high-altitude flight tests. The integration of the rocket motors with the test vehicle has to be carefully examined. Appropriate instrumentation to meet the test objectives must be defined.

\section{Acknowledgments}

Ian G. Clark provided several of the IAD images used in this paper. We thank Christopher L. Tanner and Mark Schoenenberger for their assistance. The Program to Advance Inflatable Decelerators for Atmospheric Entry (PAIDAE) and the NASA Undergraduate Student Research Program (USRP) funded this research.

\section{References}

\footnotetext{
${ }^{1}$ Braun R. D. and Manning, R. M, "Mars Exploration Entry, Descent, and Landing Challenges," Journal of Spacecraft and Rockets, Vol. 44, No. 2, 2007, pp. 310-323.

${ }^{2}$ Seiff, A., "Post-Viking Models for the Structure of the Summer Atmosphere of Mars," Advances in Space Research, Vol. 2, 1982, pp. 3-17.

${ }^{3}$ Schoenenberger, M., Queen, E. M., and Litton, D., "Oscillation Amplitude Growth for a Decelerating Object with Constant Pitch Damping," AIAA-2006-6148, 2006.

${ }^{4}$ Anon., "U.S. Standard Atmosphere, 1976," NASA TM 74335, 1976.

${ }^{5}$ Wolowicz, C. H., Bowman, J. S., and Gilbert, W. P., "Similitude Requirements and Scaling Relationships as Applied to Model Testing," NASA TP 1435, 1979.

${ }^{6}$ Askins, P. A., Zell, P. T., and Ross, J. C., “Aerodynamic Decelerator Testing in the National Full-Scale Aerodynamics Complex," AIAA-97-1528, 1997.

${ }^{7}$ Zell, P. T., Cruz, J. R., and Witkowski, A., "Structural Testing of Parachutes in the National Full-Scale Aerodynamics Complex 80-by-120-Foot Wind Tunnel at NASA Ames Research Center," AIAA-2003-2130, 2003.
} 
${ }^{8}$ Rivellini, T. and Adams, D., "Mars Science Laboratory’s Parachute Qualification Approach,” AIAA 2009-2913, 2009.

${ }^{9}$ Anon., "Guide for Planning Investigations in the Ames 40- by 80-Foot Wind Tunnel," NASA TM 108107, 1972.

${ }^{10}$ Moog, R. D. and Michel, F.C., "Balloon Launched Viking Decelerator Test Program Summary Report," NASA CR-112288, 1973.

${ }^{11}$ Alliant Techsystems Inc., “ATK Space Propulsion Products Catalog,” Elkton, MD, 2008.

Table 1. Flight and test vehicle properties.

\begin{tabular}{lccc}
\hline & $\begin{array}{c}\text { Mars Flight } \\
\text { Vehicle }\end{array}$ & $\begin{array}{c}\text { Single-Stage } \\
\text { Test Vehicle }\end{array}$ & $\begin{array}{c}\text { Two-Stage } \\
\text { Test Vehicle }\end{array}$ \\
\hline$m_{\text {vehicle }}(\mathrm{kg})$ & 5,089 & $127^{*}$ & $371^{*}$ \\
$d(\mathrm{~m})$ & 4.50 & 1.50 & 2.14 \\
$d_{I A D}(\mathrm{~m})$ & 15.0 & 5.0 & 5.0 \\
\hline
\end{tabular}

${ }^{*}$ Test vehicle mass for the powered high-altitude flight tests described in section VI.

Table 2. Flight and test vehicle initial conditions.

\begin{tabular}{lcc}
\hline & $\begin{array}{c}\text { Mars Flight } \\
\text { Vehicle }\end{array}$ & $\begin{array}{c}\text { Test } \\
\text { Vehicle }^{\#}\end{array}$ \\
\hline$M_{S D}$ & 4.0 & 4.0 \\
$\rho_{S D}\left(\mathrm{~kg} / \mathrm{m}^{3}\right)$ & $7.42 \times 10^{-3}$ & $5.01 \times 10^{-3}$ \\
$h_{S D}(\mathrm{~m})$ & $10,000^{*}$ & 33,503 \\
$a_{S D}(\mathrm{~m} / \mathrm{s})$ & 236 & 315 \\
$q_{S D}(\mathrm{kPa})$ & 3.3 & 4.0 \\
\hline
\end{tabular}

\#Applies to both the single- and two-stage vehicles for the powered high-altitude flight tests described in section VI.

*Above the reference surface of Mars.

Table 3. Analysis results for the unpowered high-altitude flight tests.

\begin{tabular}{cccc}
\hline $\begin{array}{c}\text { Test } \\
\text { Vehicle }\end{array}$ & $\begin{array}{c}\text { NASA } \\
\text { Standard } \\
\text { Balloon }\end{array}$ & Parameter \\
\hline Single- & 0.33 & $m_{\text {vehicle }}(\mathrm{kg})$ & 700 \\
Stage & million- & $h_{0}(\mathrm{~m})$ & 38,043 \\
& cubic-meter & $t_{S D}(\mathrm{~s})$ & 58.3 \\
& & $h_{S D}(\mathrm{~m})$ & 23,431 \\
& & $M_{S D}$ & 1.22 \\
Two- & 1.11 & $m_{\text {vehicle }}(\mathrm{kg})$ & 1,300 \\
Stage & million- & $h_{0}(\mathrm{~m})$ & 41,074 \\
& cubic-meter & $t_{S D}(\mathrm{~m})$ & 64.8 \\
& & $h_{S D}(\mathrm{~m})$ & 23,334 \\
& & $M_{S D}$ & 1.22 \\
\hline
\end{tabular}

Table 4. Solid rocket motor characteristics.

\begin{tabular}{ccccc}
\hline Test Vehicle & $\begin{array}{c}\text { STAR }^{\mathrm{TM}} \\
\text { Designation }\end{array}$ & $\begin{array}{c}\text { Total Impulse } \\
(\mathbf{N}-\mathbf{s})\end{array}$ & $\begin{array}{c}\text { Burn } \\
\text { Time (s) }\end{array}$ & $\begin{array}{c}\text { Average } \\
\text { Thrust (kN) }\end{array}$ \\
\hline Single-Stage & $24 \mathrm{C}$ & $6.1 \times 10^{5}$ & 28.00 & 20.7 \\
Two-Stage & $30 \mathrm{E}$ & $1.8 \times 10^{6}$ & 51.10 & 35.1 \\
\hline
\end{tabular}


Table 5. Trajectory analysis results for the powered high-altitude flight tests.

\begin{tabular}{|c|c|c|c|c|}
\hline Test & $\begin{array}{c}\text { Solid } \\
\text { Rocket }\end{array}$ & $\begin{array}{c}\text { NASA } \\
\text { Standard }\end{array}$ & \multicolumn{2}{|c|}{ Parameter } \\
\hline \multirow{3}{*}{$\begin{array}{l}\text { Single- } \\
\text { Stage }\end{array}$} & \multirow{3}{*}{$24 \mathrm{C}$} & \multirow{3}{*}{$\begin{array}{c}0.33 \\
\text { million- } \\
\text { cubic-meter }\end{array}$} & $h_{0}(\mathrm{~m})$ & 39,980 \\
\hline & & & $\theta_{0}(\mathrm{deg})$ & 5.15 \\
\hline & & & $t_{c}(\mathrm{~s})$ & 3.1 \\
\hline \multirow{3}{*}{$\begin{array}{l}\text { Two- } \\
\text { Stage }\end{array}$} & \multirow{3}{*}{$30 \mathrm{E}$} & \multirow{3}{*}{$\begin{array}{c}1.11 \\
\text { million- } \\
\text { cubic-meter }\end{array}$} & $h_{0}(\mathrm{~m})$ & 41,832 \\
\hline & & & $\theta_{0}(\mathrm{deg})$ & 9.11 \\
\hline & & & $t_{c}(\mathrm{~s})$ & 3.5 \\
\hline
\end{tabular}
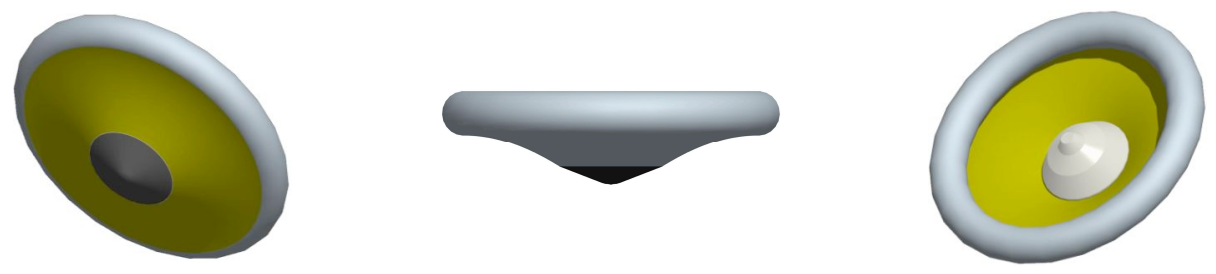

Figure 1. Tension cone inflatable aerodynamic decelerator.

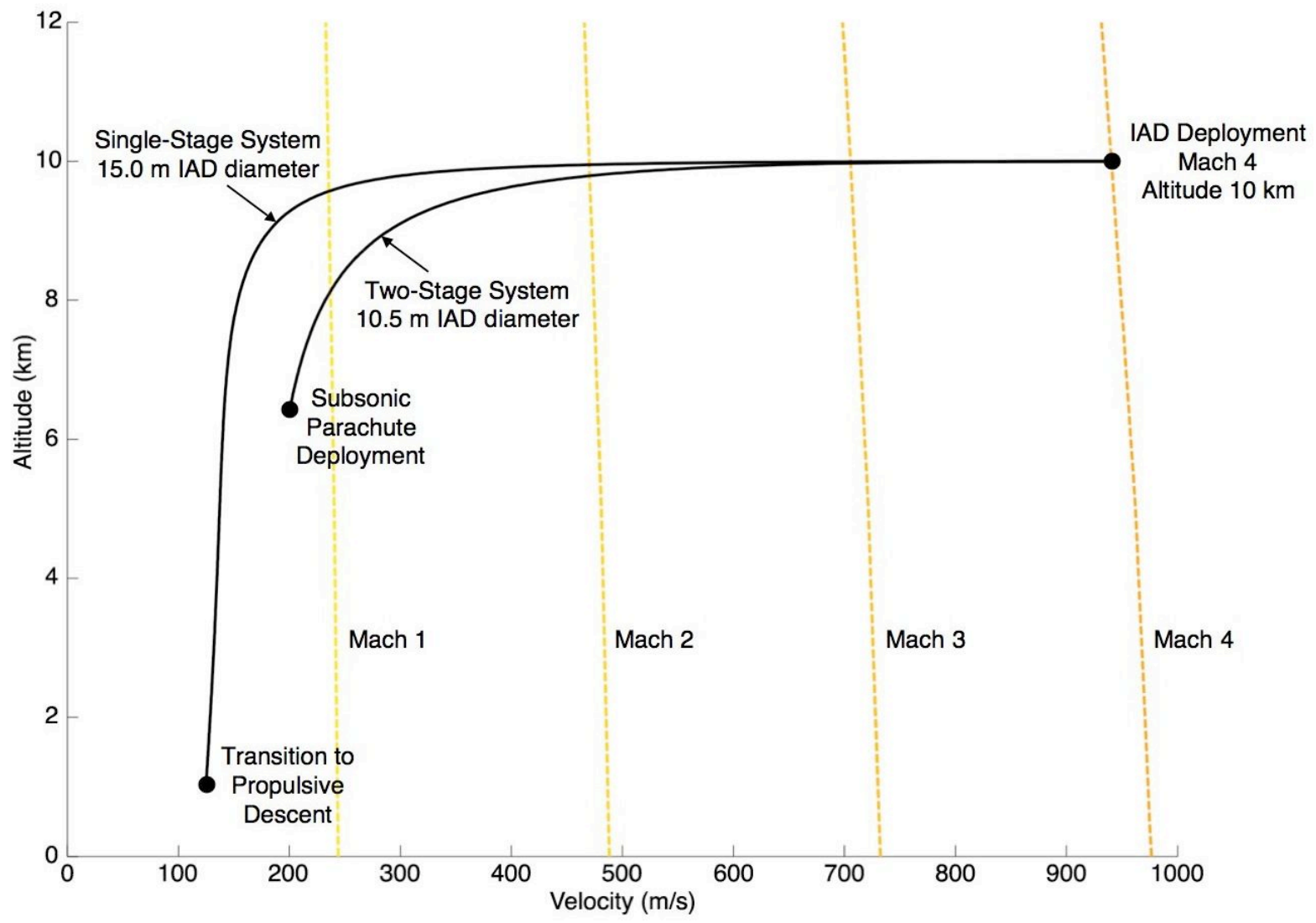

Figure 2. Mars reference trajectories for the single-stage vehicle (15.0 m IAD diameter) and two-stage vehicle (10.5 m IAD diameter). 


\section{Tunnel Ceiling}
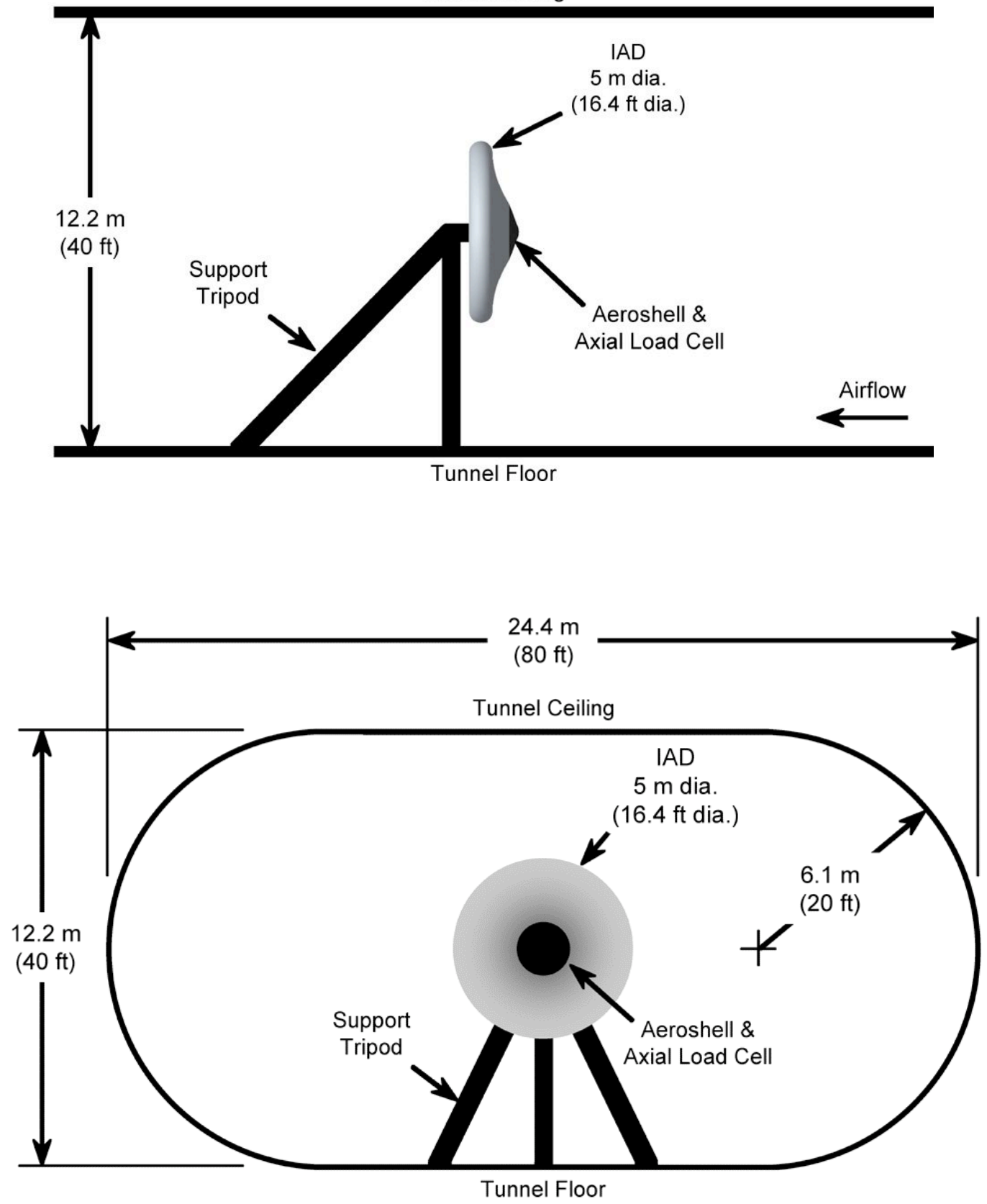

Figure 3. Side and front views of the wind tunnel test setup in the NFAC 40- by $80-\mathrm{ft}$ test section. The IAD and wind tunnel are shown to scale. 


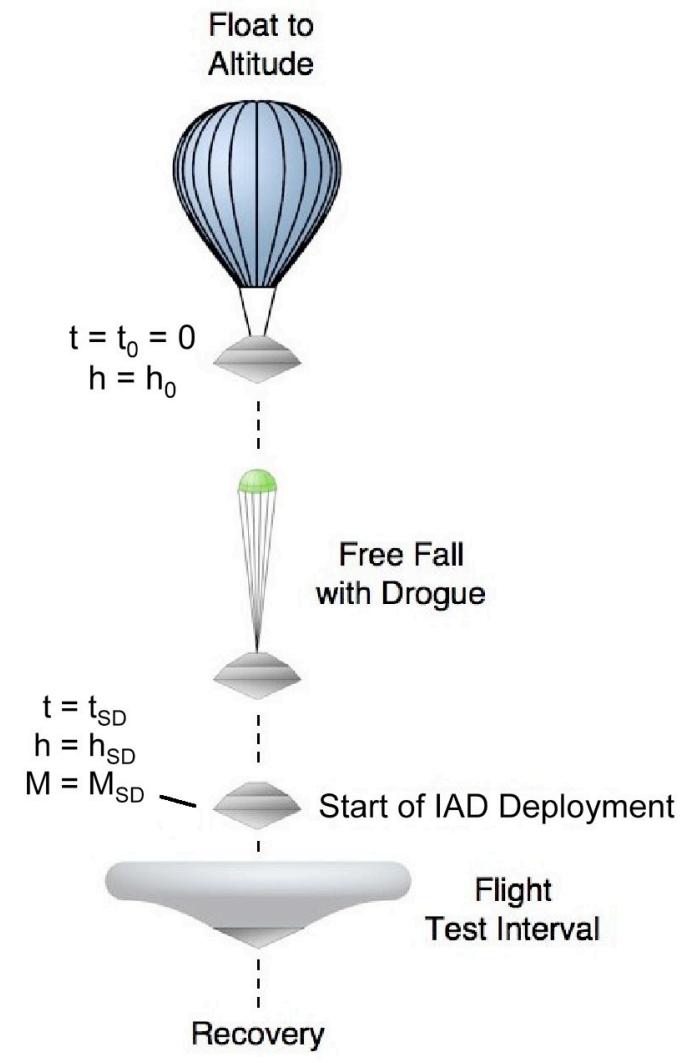

Figure 4. Unpowered high-altitude flight test concept of operation.

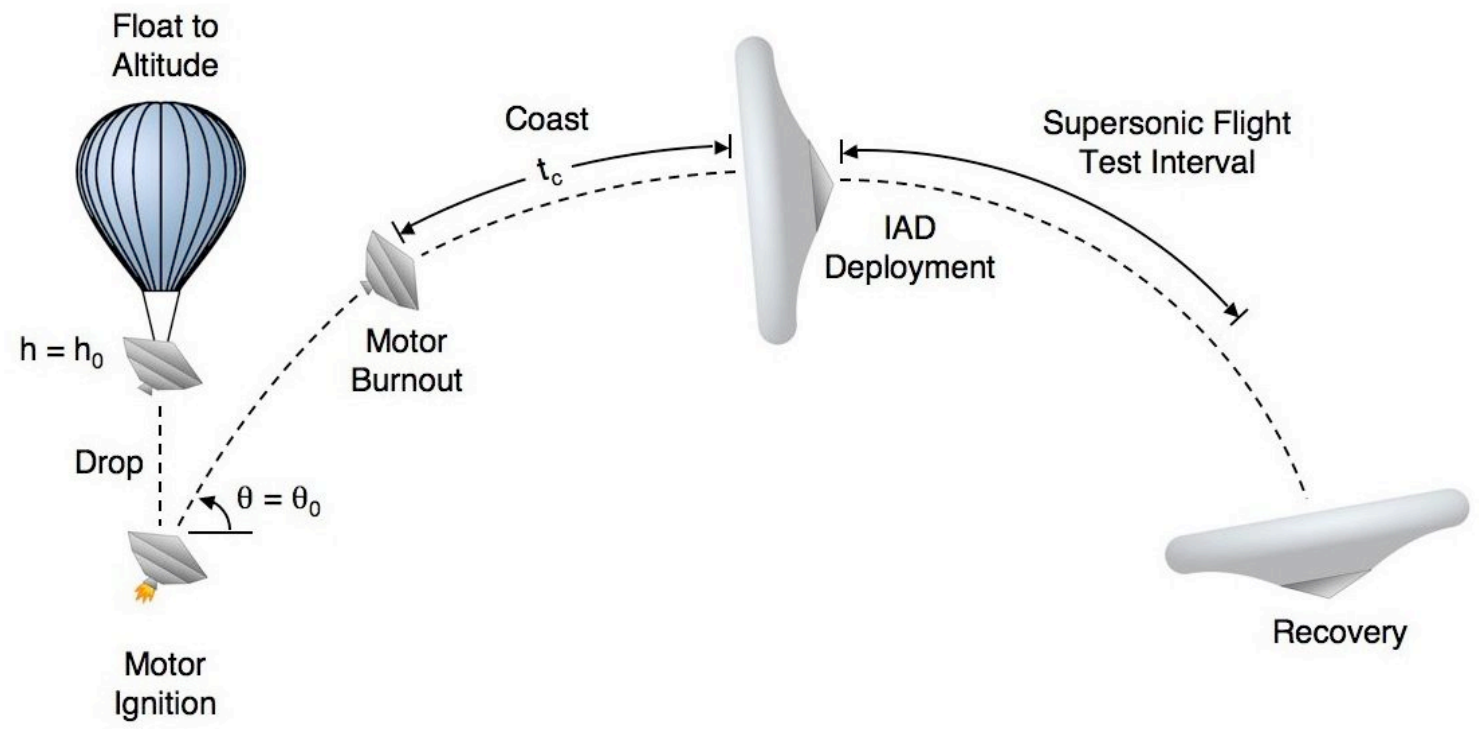

Figure 5. Powered high-altitude flight test concept of operation. 


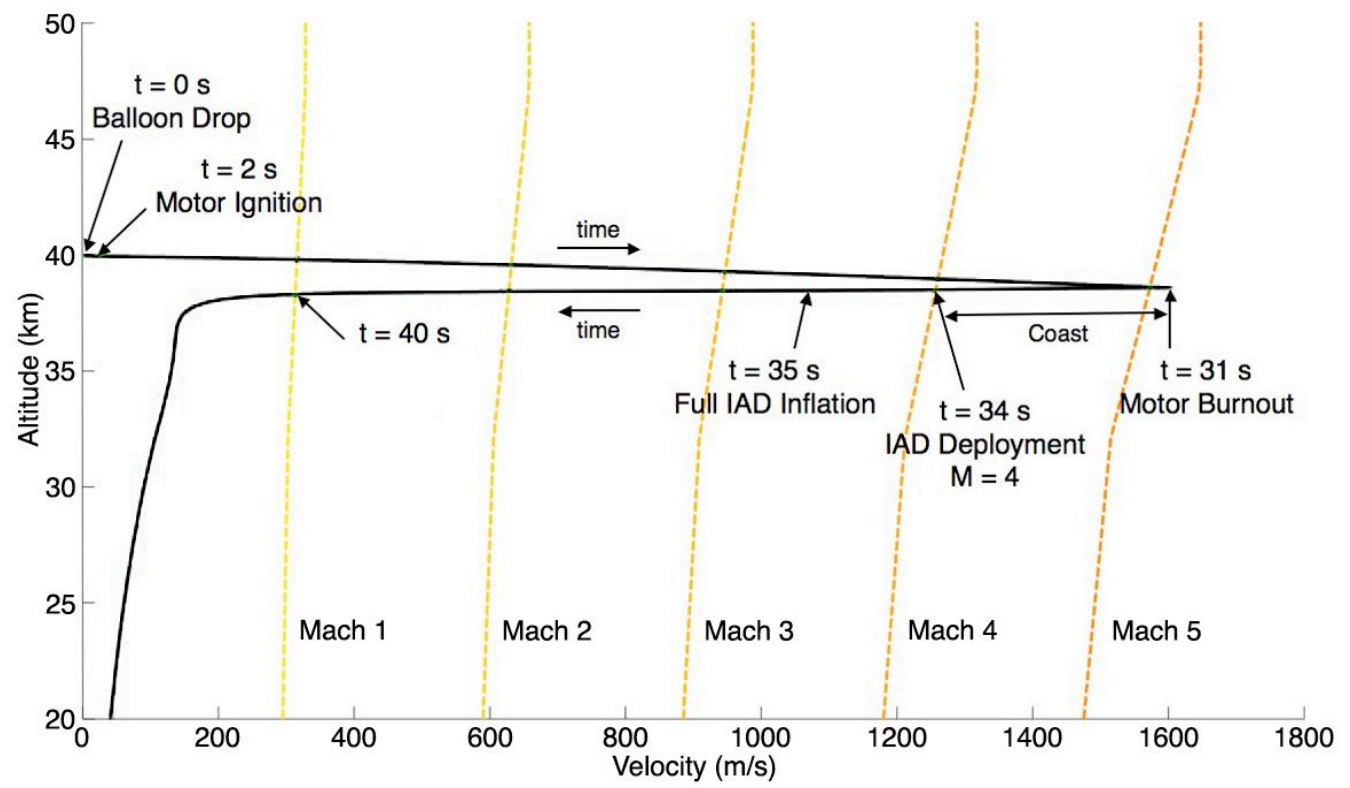

Figure 6. Altitude versus velocity trajectory profile for the single-stage test vehicle, STAR ${ }^{\mathrm{TM}} 24 \mathrm{C}$ solid rocket motor, and 0.33 million-cubic-meter NASA standard balloon.

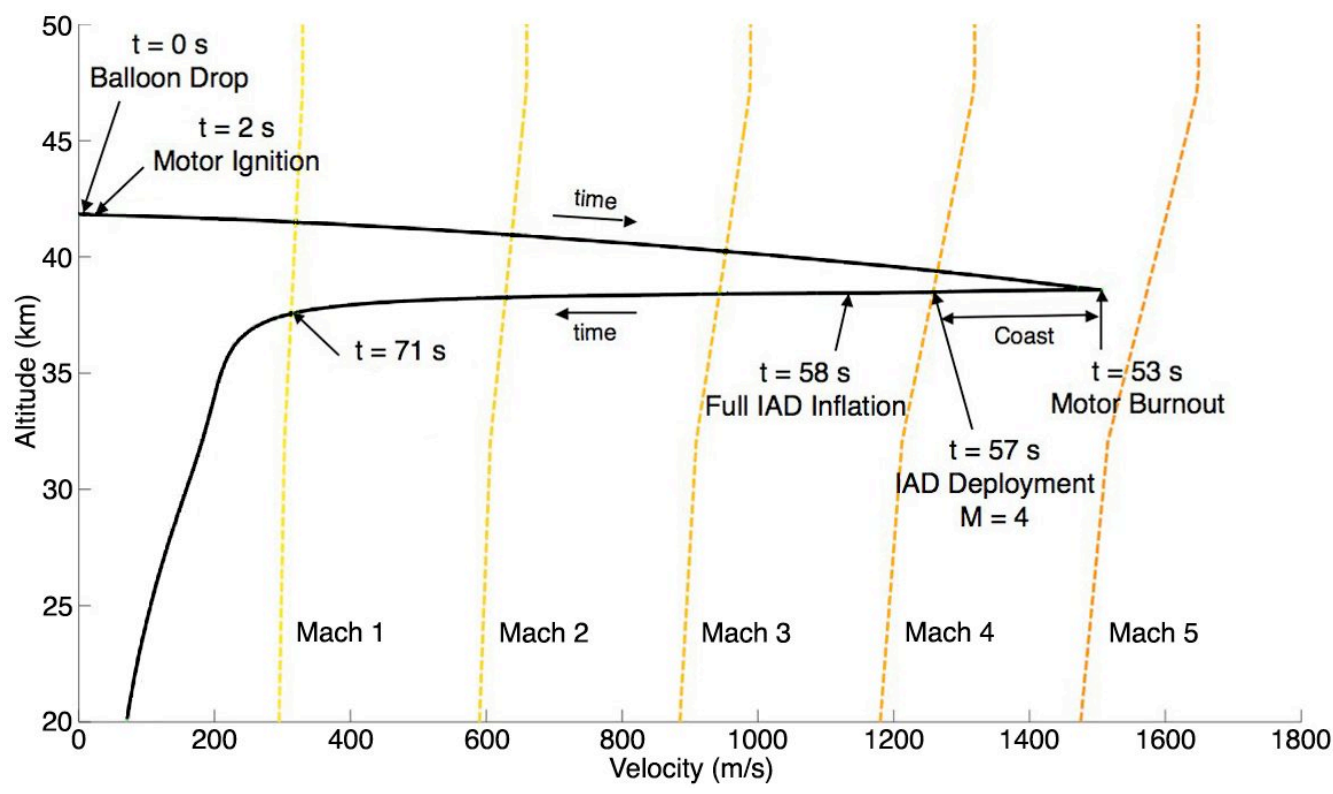

Figure 7. Altitude versus velocity trajectory profile for the two-stage test vehicle, $\mathrm{STAR}^{\mathrm{TM}} 30 \mathrm{E}$ solid rocket motor, and 1.11 million-cubic-meter NASA standard balloon.
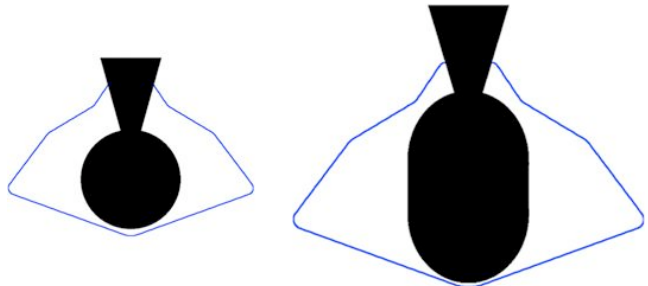

Figure 8. Sizing check showing STAR ${ }^{\mathrm{TM}} 24 \mathrm{C}$ rocket motor in single-stage aeroshell test vehicle (left) and $\mathrm{STAR}^{\mathrm{TM}} 30 \mathrm{E}$ rocket motor in two-stage aeroshell test vehicle (right). Rocket motor profiles adapted from ref. 11. 


\section{Errata}

In the first paragraph of section III.C, page 4 , the equation " $N_{d}=10.5 / 15.0=0.476$ " should read “ $N_{d}=5.0 / 10.5=0.476 "$.

Table 1 on page 8 is missing the column for the Mars two-stage flight vehicle. The corrected table is shown below.

Table 1. Flight and test vehicle properties.

\begin{tabular}{ccccc}
\hline & $\begin{array}{c}\text { Mars } \\
\text { Single-Stage } \\
\text { Flight Vehicle }\end{array}$ & $\begin{array}{c}\text { Mars } \\
\text { Two-Stage } \\
\text { Flight Vehicle }\end{array}$ & $\begin{array}{c}\text { Single-Stage } \\
\text { Test Vehicle }\end{array}$ & $\begin{array}{c}\text { Two-Stage } \\
\text { Test Vehicle }\end{array}$ \\
\hline$m_{\text {vehicle }}(\mathrm{kg})$ & 5,089 & 5,089 & $127^{*}$ & $371^{*}$ \\
$d(\mathrm{~m})$ & 4.50 & 4.50 & 1.50 & 2.14 \\
$d_{I A D}(\mathrm{~m})$ & 15.0 & 10.5 & 5.0 & 5.0 \\
\hline${ }^{*}$ Test vehicle mass for the powered high-altitude flight tests described in section VI.
\end{tabular}

In the first paragraph of section V.C on page 5, the peak aerodynamic force for the single-stage vehicle is $78.2 \mathrm{kN}$ (missing units). 